\title{
Differenz
}

Revista internacional de estudios heideggerianos y sus derivas contemporáneas

AÑO 7, NÚMERO 6: JULIO DE 2020. ISSN 2386-4877 - DOI: 10.12795/Differenz.2020.i06.01

[pp. 11-30]

Recibido: 07/06/2020

Aceptado: 29/06/2020

\section{La nada, el tedio y la técnica: reflexiones de Heidegger sobre el nihilismo.}

\section{Nothingness, boredom and technology: Heidegger's reflections on nihilism.}

\author{
Ernesto Baltar \\ Universidad Rey Juan Carlos
}

Resumen:

En este artículo nos proponemos analizar la múltiple y ambivalente relación entre los conceptos de la nada, el tedio y la técnica en el pensamiento de Martin Heidegger. Tanto la pregunta por la nada, que va más allá del ente en su totalidad, como la pregunta por la técnica, que es una forma de acceso al ser, son cuestiones fundamentales para Heidegger que hay que plantear para hacer viable de nuevo la pregunta por el ser. La analítica existencial del tedio, que facilita el acceso al fundamento de la existencia, demarca un ámbito común donde pueden "engranar" los tres conceptos.

Palabras clave: Nihilismo; Aburrimiento; Técnica; Maquinación; Nada; Ser. 


\section{Abstract:}

In this paper we try to analyze the multiple and ambivalent relationship between the concepts of nothingness, boredom and technology in Martin Heidegger's philosophy. Both the question about nothing, which goes beyond the entity as a whole, and the question about technique, which is a form of access to being, are fundamental questions for Heidegger that must be asked to make the question of Being possible again. The existential analytic of boredom, which provides access to the foundation of existence, points a common environment where the three concepts can be "engaged".

Keywords: Nihilism; Boredom; Technique; Machination; Nothing; Being.

\section{Introducción.}

Tanto la pregunta por la nada, que va más allá del ente en su totalidad, como la pregunta por la técnica, que es una forma de acceso al ser, son cuestiones fundamentales para Heidegger, interrogaciones que es preciso formular para hacer viable de nuevo la pregunta por el ser. En este artículo nos proponemos indagar si la analítica existencial del tedio, que facilita el acceso al fundamento de la existencia, puede demarcar un ámbito común que sirva de "engranaje" de los tres conceptos. De este modo, analizaremos la múltiple y ambivalente relación que existe, en el pensamiento de Heidegger, entre los conceptos de la nada, el tedio y la técnica.

Aunque la reflexión de Heidegger sobre el nihilismo (Nihilismus) se inicia propiamente con el viraje (Kehre) que efectúa su filosofía a partir de sus cursos sobre Nietzsche en la Universidad de Friburgo (1936-1946), donde aparece enmarcado en el problema de la metafísica y de su historia, desde los comienzos de su obra estuvo muy presente la cuestión de la nada (Nichts), que remite a la constitución de la estructura fundante de la existencia. La pregunta filosófica por antonomasia según Heidegger -"¿por qué es el ente y no más bien la nada?"- expone al ente a la posibilidad del no-ser. Al preguntar por el ser, como lo más digno de ser preguntado, tenemos que llevar nuestra interrogación hasta el extremo de interrogarnos por la nada. No basta con preguntarse por aquello frente a lo cual se ha delimitado tradicionalmente el ser, ya sea el devenir, la apariencia, el pensar o el deber ser $^{1}$. Para Heidegger el nihilismo consiste en el olvido y el abandono del ser, borrando la diferencia ontológica en favor del ente. Este olvido se corresponde con la historia de la

1 "¿Acaso el devenir es nada? ¿La apariencia es nada? ¿El pensar es nada? ¿El deber ser es nada? De ninguna manera podemos afirmar eso", sentencia categóricamente Heidegger en Introducción a la metafísica (Barcelona, Gedisa, 1987, p. 181). 
metafísica, que ha sentado las bases de la racionalidad vacía, del pensamiento calculador, de la tecnificación omnímoda. El ser se ha visto "entificado" y, por ende, "tecnificado". El abandono del ser es el indicio del nihilismo consumado, la última fase de la metafísica: "La metafísica en cuanto metafísica es el auténtico nihilismo"2 . Y precisamente "el primer y único paso eficaz para una verdadera superación del nihilismo" ${ }^{13}$ implica avanzar hasta los límites de la nada en la pregunta por el ser e incluir la nada en esta pregunta.

Ya explicaba Ernst Jünger en Sobre la línea que la gran dificultad para poder definir el nihilismo reside en que no podemos hacer una representación de la Nada: no podemos tener de ella ni una imagen ni un concepto ${ }^{4}$. En el caso de Heidegger, hay una presencia necesaria -se puede hablar, incluso, de una primacía- de la negatividad, una especie de "negatividad activa" que en Ser y tiempo sólo fue analizada como existenciario y que después fue abordada directamente en sí misma en distintos escritos como ¿Qué es metafísica?, Los conceptos fundamentales de la metafísica: Mundo, finitud, soledad, Introducción a la metafísica o Contribuciones a la filosofía (Del acontecimiento), entre otros. Para Heidegger, como decíamos, la pregunta por el ser incluye necesariamente la pregunta por la nada, y es preciso enfrentarse a esta interrogación sobre la nada para poder superar el nihilismo de nuestra época de tecnificación planetaria, uniformización de los estilos de vida y planificación sistemática de todos los dominios del ente.

\section{La nada en su relación con la ciencia y la técnica.}

En ¿Qué es metafísica? Heidegger plantea la cuestión de la nada en su relación con la ciencia y la técnica. Aunque el científico no utilice de manera explícita el concepto de nada, lo está empleando de manera implícita al deslindar lo que es científico y lo que no lo es. El científico delimita su ámbito de saber seguro, en el que las cosas se muestran en su verdadera realidad, ya que su objeto de investigación es el ente, lo que es. Quedan así desechados los demás ámbitos, que no tienen nada de científico porque se alejan de las cosas tal como son. Por eso, según Heidegger, se puede afirmar que la ciencia se preocupa del ente y de "nada" más. Lo otro del ente (el no-ente, el ser) no le interesa a la ciencia.

Si bien la ciencia "no quiere saber nada de la nada"5, hace un uso explícito de la negación en el "principio de no contradicción". En cuanto a la negación y la nada, se pregunta

2 HeIDEgGER, M. Nietzsche II. Barcelona, Destino, 2000, p. 343.

3 HeIDEGgeR, M. Introducción a la metafísica. Op. cit., p. 181.

4 Cfr. Jünger, E. "Sobre la línea", en Heidegger, M.; Jünger, E. Acerca del nihilismo. Barcelona, Paidós, 1994, p. 25.

5 Heidegger, M. ¿Qué es metafísica?. Buenos Aires, Siglo Veinte, 1967, p. 42. 
Heidegger cuál de las dos tiene prioridad: ¿de cuál de ellas deriva la otra? Finalmente opta por la prioridad de la nada frente a la mera negación lógica, en cuanto acción del entendimiento. Ya en su tesis de 1913 sobre La doctrina del juicio en el psicologismo, bajo la dirección de Arthur Schneider, había investigado Heidegger la negación en el juicio, entendiendo su significado como el "no darse algo determinado" y llegando a la conclusión de que puede abstraerse una nada meramente pensada a partir del "no", pero que la nada no existe en realidad.

La nada, como "negación pura y simple de la omnitud del ente"6, es aquello que la ciencia no quiere tratar. Estamos, pues, ante dos extremos: la totalidad del ente y la nada. Mientras que la primera se revela en la experiencia profunda del aburrimiento, la segunda se nos muestra en el temple de la angustia. Ambas afecciones -aburrimiento y angustiano refieren a algo concreto o determinado, sino que implican que todas las cosas, todos los demás y nosotros mismos nos hundimos en un estado de indiferencia. Se abre así una dimensión diferente del ente. En la experiencia de la angustia se nos da una revelación del ser (de la nada) como distinto de todo ente. La afección del aburrimiento la analizaremos en extenso en el siguiente epígrafe.

De la conciencia de que no nos queda ningún soporte ni fundamento emana la convicción de que "la nada misma, en cuanto tal, estaba allí"7. La acción de la nada revela el ente en su plena extrañeza como lo totalmente otro frente a la nada, creando un ámbito de trascendencia frente al ente en su totalidad. En este sentido, la nada crea la apertura del ente: "existir (ek-sistir) significa: estar sosteniéndose dentro de la nada"8. Manteniéndose en la nada, el ser-ahí está ya más allá del ente en su totalidad, pudiendo comportarse con el ente y consigo mismo ${ }^{9}$. En eso consiste la trascendencia que se abre.

De este modo, Heidegger explicita la negatividad inherente a la existencia que había apuntado en Ser y tiempo. La nada adquiere tal importancia que podemos afirmar que, sin la patencia originaria de la nada, el hombre no podría dirigirse al ente, no habría ningún sí mismo ni sería posible la libertad. La nada misma se convierte en lo que da el ser al hombre: "La existencia se encuentra sacudida por el anonadar de la nada"10.

\footnotetext{
$6 \mathrm{lb} .$, p. 44.

7 lb., p. 49

$8 \mathrm{lb}$.

9 Cfr. GABÁs, R. "La realidad de la nada", en "Martin Heidegger: Caminos hacia el ser", en HIRSCHBERGER, J. Historia de la Filosofía III. Filosofía del siglo XX. Barcelona, Herder, 2011. 10 HeIDEgGER, M. ¿Qué es la metafísica? Op. cit., p. 51.
} 
En Introducción a la metafísica Heidegger reconoce que hablar de la nada sigue siendo contrario al pensamiento en general y destructor en particular, y se pregunta:

¿qué haríamos si tanto la preocupación por el debido respeto a las reglas fundamentales del pensamiento como la angustia ante el nihilismo -ambos nos podrían desaconsejar hablar de la nada- se debieran a un malentendido ${ }^{11}$

Este malentendido tiene su origen en una incomprensión de la pregunta por el ente, que a su vez se deriva del olvido del ser. Como explica Emanuele Severino, el pensamiento se ha sumido de tal modo en el olvido de la verdad del ser

que no se da cuenta de que el ser del ente es su propio no ser nada, y que aquí se está en lo hondo del pensar, en la verdad originaria, sobre la que no se puede interrogar porque la interrogación es también un modo de negarla ${ }^{12}$.

El pensamiento tradicional que sólo se atiene a las leyes de la lógica es incapaz, según Heidegger, de comprender la pregunta por el ser, pues cuando invocan el principio de contradicción y la lógica para demostrar la contradicción inherente a todo pensar sobre la nada están considerando la lógica "como un tribunal asegurado desde la eternidad"13. No se puede hablar de la nada como si fuese una cosa. Por principio, la nada sigue siendo inaccesible a toda ciencia, y quien pretenda hablar verdaderamente de ella, tendrá que convertirse necesariamente en acientífico. La vinculación de la técnica con la verdad que Heidegger establecerá posteriormente conlleva una comprensión de la técnica como origen, que no deriva de nada: la técnica es un "sacar a la luz", un "traer delante" lo que antes no estaba, y por eso mismo es previa a cualquier conocimiento, incluida la ciencia. Lo que hace la ciencia es delimitar y conceptualizar el ámbito ya abierto previamente por la técnica ${ }^{14}$.

Se da la aparente paradoja de que el hombre trasciende hacia la nada y, al mismo tiempo, es la nada la que abre la trascendencia hacia el ente. El Dasein es un ente que implica ser e implica nada. El Dasein es estar sosteniéndose dentro de la nada del Ser (Seyn), sosteniéndose en cuanto comportamiento (Verhaltnis). Tanto en la estructura de la

11 HEIDEGGER, M. Introducción a la metafísica. Op. cit., p. 31

12 SeVerino, E. Essenza del nichilismo. Milano, Adelphi, 2005, p. 81.

13 HeIDEGgER, M. Introducción a la metafísica. Op. cit., p. 33.

14 Cfr. LeYTE, A. Heidegger. Madrid, Alianza, 2005, p. 224. 
condición de arrojado como en la del proyecto, se da esencialmente una nihilidad ${ }^{15}$. Y ella es el fundamento de posibilidad de la nihilidad del Dasein impropio en la caída, en la cual el Dasein está siempre fácticamente. El cuidado mismo está, en su esencia, enteramente impregnado de nihilidad. El cuidado -el ser del Dasein- consiste, por consiguiente, en cuanto proyecto arrojado, en ser-fundamento (negativo) de una nihilidad. La nihilidad existencial no tiene el carácter de una privación, de una deficiencia respecto de un ideal propuesto y no alcanzado en el existir, sino que el ser de este ente es ya de por sí negativo en cuanto proyectar. Por consiguiente, esta nihilidad no aparece ocasionalmente en el Dasein, sino de manera permanente.

Heidegger viene a afirmar que el ser y la nada son lo mismo, ya que "el ser es, por esencia, finito, y solamente se patentiza en la trascendencia de la existencia que sobrenada en la nada"16. Como nada (como ser), el Dasein es un ente que es trascendente frente al ente, y como ente se comporta con la nada. En esa referencia recíproca entre el ente y la nada reside la peculiaridad de la existencia humana y el origen de su reflexividad y de su ser sí mismo. Por tanto, aunque el científico quisiera desentenderse de la nada, su obra sólo es posible si él se mantiene en la nada: "La existencia científica sólo es posible si, de antemano, se encuentra sumergida en la nada"17. Sin la extrañeza ante el ente, sin la pregunta por el porqué, que busca razones y trata de fundar el ser, no es posible el conocimiento ni la existencia humana.

La metafísica es el acontecer fundamental del Dasein, pertenece a la naturaleza del hombre. El ser simplemente se da, y el tipo de relación que el hombre guarda con el ser queda fijado por el modo como cada época histórica determina ese darse del ser. Pues bien, en la actualidad el hombre vive inmerso en una concepción del mundo exclusivamente técnica. La empresa de Heidegger no es fundar una ontología, sino precisamente destruir la ontología; por eso anota la tarea que le espera: "abrirle un cauce en el concepto a la diferencia de ser". La era de la metafísica no sólo está marcada por el olvido del ser sino también por su abandono. Es el indicio del nihilismo consumado, el final de la modernidad, la última fase de la metafísica. El ente ya no encuentra el vínculo que lo liga al ser, y el Ser se retrae. Es la noche del Ser.

15 Como explica Jorge Eduardo Rivera, la nihilidad en alemán es Nichtigkeit, habitualmente traducida como "nulidad", "futilidad", "inanidad" o "negatividad". Derivada del latín nihil, José Gaos tradujo Nichtigkeit por "no ser", que viene a decir lo mismo que nihilidad. Significa la "noidad", es decir, el carácter de no que tiene alguna cosa. Heidegger habla del sentido ontológico de la negatividad de la "nihilidad existencial". Cfr. HeIDEgGER, M. Ser y tiempo. Madrid, Trotta, 2018.

16 HeIdEGGER, M. ¿Qué es la metafísica? Op. cit., p. 54.

17 lb., p. 55 
Para Heidegger urge "el conocimiento y reconocimiento de la esencia del nihilismo"18, pues, vuelto patente en su "irresistibilidad multiforme que lo devora todo"19, el movimiento del nihilismo no ha sido detenido ni desviado por las dos guerras mundiales y se ha convertido una amenaza planetaria que "no es curable ni incurable"20. El nihilismo se ha consumado y es el estado normal de la humanidad. Para poder pensar las posibilidades esenciales del nihilismo hay que pensar de nuevo su esencia. La pregunta que sigue en pie es la siguiente: "¿Desaparece la Nada con la consumación o, al menos, con la superación del nihilismo?"21. Y Heidegger responde:

Presumiblemente sólo se llega a esta superación si en lugar de la apariencia de la Nada anonadante llega la esencia de la Nada transformada en el "Ser" y puede alojarse en nosotros mortales ${ }^{22}$.

\section{El tedio en su relación con la nada y la técnica.}

Dado que lo más próximo y originario es nuestro anclaje afectivo en el mundo, el acontecimiento del ser se manifiesta básicamente a partir de un conjunto de estados de ánimo como el espanto, la contención, el júbilo, el asombro, la angustia, la preocupación, el éxtasis o el aburrimiento, que Heidegger va analizando. En ¿Qué es la filosofía? Heidegger subraya la importancia de estas afecciones fundamentales, puesto que el pensamiento esencial arranca de ellas y sólo desde ellas experimentamos el mundo. Incluso

la frialdad del cálculo y la prosaica sobriedad de la planificación son signos característicos de una disposición anímica (...). La razón misma, que se considera libre de todo influjo de las pasiones, está dispuesta a confiar en la evidencia lógico-matemática de sus principios y de sus reglas ${ }^{23}$.

Para Heidegger los estados de ánimo son los presupuestos básicos del pensamiento y de la acción humana ${ }^{24}$. Vivimos en una proximidad inmediata con las cosas de la vida que la filosofía debe saber captar y entender, superando la disposición utilitaria que reduce los seres a instrumentos y enfocándonos en su iluminación.

18 HeIdegGer, M. "Hacia la pregunta del ser". En HeIdegGer, M.; Jünger, E. Op. cit., p. 76. 19 lb., p. 77.

20 lb., p. 82.

21 lb., p. 106.

$22 \mathrm{lb}$.

23 HeIDEgGer, M. ¿Qué es la filosofía?. Barcelona, Herder, 2004, p. 64.

24 Cfr. GUMBRECHT, H. U. Stimmungen lesen: über eine verdeckte Wirklichkeit der Literatur. Múnich, Hanser, 2011, p. 125. 
En las lecciones sobre Los conceptos fundamentales de la metafísica: Mundo, finitud, soledad, Heidegger analiza el aburrimiento como una estructura de fondo de la experiencia, una manera de "ser-en-el-mundo", una orientación existencial que abarca la experiencia, el pensamiento, la voluntad y la acción y que es capaz de modificar comportamientos y moldear nuestras formas de relacionarnos con el mundo y con los otros $^{25}$. Heidegger caracteriza el aburrimiento como "una especial afección paralizadora del curso del tiempo y del tiempo en general"26. Los tres modos de aburrimiento principales que distingue Heidegger -aburrirse de algo, aburrirse con algo y la forma más profunda y filosófica de aburrimiento: el tedio- revelan relaciones distintas entre la temporalidad de la existencia humana y lo que se podría llamar el significado de la vida. En el aburrimiento experimentamos un tiempo vacío que tenemos que llenar de alguna manera pero que no queda incorporado a ninguno de nuestros proyectos. También podemos caer en el aburrimiento cuando nos vemos obligados a realizar actividades que no forman parte de nosotros mismos, de nuestra mismidad, y en consecuencia se produce un vacío en nosotros.

La forma más profunda de aburrimiento, correspondiente a la expresión "uno se aburre", es la situación en la que nada nos dice nada y todo nos deja en la indiferencia, sin que haya una causa o motivación determinada. El ente en su totalidad se vuelve indiferente. En esas situaciones de tedio el Dasein no busca posibilidades en los entes y prescinde del tiempo; no hay resolución ni mirada para la acción. Es como si los instantes desapareciesen y la existencia quedase en suspenso. En el fondo es el propio tiempo el que expulsa al Dasein mediante la afección del "uno se aburre". Cuando el aburrimiento lo abarca todo, sentimos nuestro total anonimato y la falta absoluta de relación con el mundo: el yo se convierte en un "indiferenciado nadie". Nada importa ya, la experiencia del mundo ha perdido su significado, todo es irrelevante e indiferente. De este modo se perfila la conexión del aburrimiento metafísico o el tedio con la nada o la nihilidad: quien experimenta el tedio es una nada, un nadie, un no-yo en un mundo carente de significación, puesto que su relación con el mundo se reduce a la total indiferencia.

Por otro lado, el tedio es una afección fundamental que tiene la virtud de introducirnos en profundidad en la problemática del ser y del tiempo ${ }^{27}$. El tedio anuncia las posibilidades del ser que estaban latentes y abre al hombre al horizonte temporal en todas sus

25 Cfr. Slaby, J. "The other side of existence: Heidegger on boredom", en FlaCH, S., MARGULIES, D. y SÖFFNER, J. (Eds.). Habitus in Habitat II - Other Sides of Cognition. Bern, Lang, 2010, pp. 101-120.

26 HeIDEGGER, M. Los conceptos fundamentales de la metafísica: Mundo, finitud, soledad. Madrid, Alianza, 2007, p. 148.

27 Cfr. SVendSEN, L. Filosofía del tedio. Barcelona, Tusquets, 2006, p. 148. 
dimensiones de pasado, presente y futuro. La temporalidad de la existencia, la constitución temporal de nuestro propio ser y el significado de la existencia estarían cohesionados inextrincablemente y comportarían una experiencia que se iría intensificando a medida que pasásemos de un estado a otro ${ }^{28}$. En el tedio el tiempo pasa sin más y el vacío surge de nuestra propia creación, afectando a la totalidad de la situación que vivimos. En la raíz del vacío se encuentran experiencias que no son significativas para nuestra vida, que son superficiales y poco comprometedoras. La situación es existencialmente irrelevante para nosotros y por lo tanto nuestra participación en la misma nos deja vacíos. El tedio se va concentrando cada vez más en nosotros.

La capacidad de asombro que la naturaleza despertaba en el hombre antiguo y que filósofos como Platón y Aristóteles erigieron como afección fundacional de la filosofía ha desaparecido en el mundo contemporáneo: nuestras formas de existencia están sumergidas en la monotonía, el tedio y la rutina. Como apunta Heidegger en sus lecciones sobre Heráclito (1943-1944), la vida contemporánea está marcada por el tedio y el vacío, que se arrojan sobre el hombre siempre que no puede entretenerse yendo al cine, escuchando la radio, leyendo el periódico, asistiendo a un concierto o realizando un viaje. Reducido el mundo a un gigantesco engranaje tecnológico de ocupaciones y diversiones, el hombre contemporáneo se siente perdido y atrapado en una vida inauténtica. La ciencia y la técnica han acabado con la sorpresa y el asombro. Todo aparece determinado por leyes causales ${ }^{29}$. Hemos perdido el contacto directo con la realidad y se ha roto la armonía del hombre con el ser. Vivimos inmersos en el tedio y la monotonía de una vida totalmente planificada.

\section{La técnica en su relación con la nada y el tedio.}

Tras un esbozo de aproximación pragmática a la técnica en las páginas de Ser y tiempo ${ }^{30}$, Heidegger articuló de forma más sólida sus posiciones fundamentales sobre la técnica en

28 Cfr. MANSiKKA, J. E. "Can boredom educate us? Tracing a mood in Heidegger's fundamental ontology from an educational point of view", en Studies in Philosophy and Education. № 28, 3, 2009, p. 260.

29 Entregado a la eficacia de la ciencia y de la técnica, el hombre moderno parecía sentirse seguro de sí mismo y se erigía en dominador de todo cuanto le rodeaba. Partiendo de la certeza de que la naturaleza se somete a principios mecanicistas (Descartes), de que la realidad puede interpretarse en términos matemáticos (Galileo) y de que el universo obedece a leyes universales (Newton), la ciencia moderna inició ese proceso gradual de control y dominio de la naturaleza que en el siglo XX fue llevado al límite, ofreciendo su cara más oscura.

30 En Ser y tiempo, dentro del marco trascendental de la investigación, Heidegger subrayaba el protagonismo de las manos, de la manipulación instrumental y técnica de los aparatos y las cosas, 
La pregunta por la técnica, Carta sobre el humanismo y Construir, habitar, pensar, aunque también trató la cuestión en otros textos ${ }^{31}$. En La época de la imagen del mundo Heidegger apuntó el papel esencial de la técnica, que no se limitaba a ser una mera aplicación de la ciencia moderna. El descubrimiento de la esencia metafísica de la técnica revelaría que no son los hombres los que manejan la técnica, como siempre se había pensado, sino que es más bien la técnica la que utiliza y manipula a los seres humanos.

En La pregunta por la técnica Heidegger parte de la idea de que la esencia de la técnica no se agota en lo instrumental, no es mero "procedimiento para", sino que es una forma de plantearnos la realidad y de concebirnos a nosotros mismos ante ella. La técnica es, por tanto, una forma de acceder al ser, de comprenderlo como realidad y de situarnos nosotros mismos ante esa realidad. Llevando el argumento a sus últimas consecuencias históricas, Heidegger concluye que la técnica es la forma de ser del hombre moderno, su manera de estar en el mundo, de comprender la realidad y de moverse en la existencia. Ahí reside el cumplimiento de un "destino" que venía ya anunciado en la cosificación de la realidad establecida por las metafísicas de Platón y Aristóteles.

La metafísica habría preparado la transformación de la naturaleza en técnica desde el momento en que descubre su propio ser. Cuando el Dasein revela su constitución como ser, como "lugar" y "claro" del ser, entonces la técnica se instituye como el lugar de descubrimiento de la naturaleza y de lo humano. El conjunto de la realidad sólo resulta comprensible a partir de la técnica, ya que ésta se ha convertido en el modo de la verdad, en el desocultamiento de todo ente. De esta manera, la técnica se constituye en la forma definitiva de comprensión del ser.

En Carta sobre el humanismo denuncia Heidegger la limitación del pensamiento griego que no separa suficientemente el concepto de técnica de sus nociones de ser y de teoría. Para Heidegger hay que volver a plantear, de manera muy distinta, la relación entre la producción y el conocimiento. La técnica no es un modo de ser entre otros posibles ni un simple procedimiento de fabricación, sino la puesta en evidencia del propio modo de producir las cosas: la propia estructura de la cosa es la representación.

frente al conocimiento, como si esa manipulación produjera ya una transformación de la realidad sobre la cual se asentaba después la ciencia. En el contexto de la analítica existencial del Dasein, estas ideas se vinculaban a la relación inmediata y "a la mano" que el hombre tiene con las cosas del mundo, que nos resultan conocidas ya antes de que las dotemos de significado o de que caigan bajo un concepto científico.

31 La cuestión de la crítica a la técnica se puede rastrear en distintas obras del Heidegger posterior al viraje: Contribuciones a la filosofía (1936/38), La época de la imagen del mundo (1938), Carta sobre el humanismo (1946), La pregunta por la técnica (1953), ¿Qué significa pensar? (1954), Serenidad (1955), ¿Qué es la filosofía? (1956), Identidad y diferencia (1957) o De camino al habla (1959). 
La técnica exige el descubrimiento y la exposición de sus propias condiciones, de modo que no sólo comparece el ser sino también su sentido. Es un proceso de desvelamiento o desocultamiento por el que aparecen no solo las cosas como productos, sino también sus condiciones de posibilidad. De este modo, en el ámbito de la técnica coinciden el ser y la representación de las cosas. Por eso la técnica y la metafísica coinciden en su esencia: el desencubrimiento total y general de lo ente. Si hay una esencia metafísica de la técnica es porque hay una esencia técnica de la metafísica ${ }^{32}$.

Por otra parte, la técnica en sí misma, como determinación indiferenciada del ser, no tiene contenido ni significado alguno. La técnica no es nada. De este modo, la técnica y el nihilismo también se corresponden: en ellos no hay nada y todo se encuentra indiferenciado. No hay concepto capaz de referir al propio vacío sino el ser mismo, es decir, su nada despojada de cualidades ${ }^{33}$. A la vaciedad y uniformidad del ser correspondería la vaciedad de su concepto. Para describir esta situación, Heidegger introduce el término neutro das Gestel/34.

La esencia de la técnica moderna es una forma concreta de "producir-conocer" que Heidegger denomina Gestell: es una manera que el hombre tiene de "traer ahí delante" las cosas, de sacar lo oculto del ser, de emplazar a los seres para que sean de determinada forma y sirvan para cumplir determinadas funciones. Esta disposición no sólo determina nuestra manera de tener presente la realidad sino nuestra propia condición humana:

Designa la actitud de dominio del hombre sobre el ente, una actitud por la que no dejamos que las cosas sean, sino que imponemos a todo el servicio que ha de prestar al conjunto organizado del mundo técnico. Exigimos a la naturaleza los materiales que ella nos ha de dar de acuerdo con el proyecto organizado ${ }^{35}$.

Para Heidegger el hombre de la era de la técnica se encuentra bajo esa provocación del hacer salir lo oculto de la realidad, sobre todo de la naturaleza como fuente de energía. El modo de representar de la ciencia moderna se pliega también a esta necesidad de tomar la naturaleza como una trama de fuerzas calculable:

32 La técnica es la metafísica consumada: lo que se verifica como mundo científico-técnico ya había comenzado en el primado metafísico de la representación y la conversión de la filosofía en una técnica de explicación por las causas últimas.

33 Cfr. LeYTE, A. Op. cit., pp. 223-224.

34 Traducido como "engranaje", "imposición", "tinglado", "dispositivo", "armazón", "estructura", "lo dispuesto" o "la estructura de emplazamiento", Gestell es el título de una conferencia impartida por Heidegger en el Club de Bremen en 1949.

35 GABÁs, R. Op. cit., p. 103. 
Por eso la física de la época moderna no es física experimental porque emplee aparatos para preguntar a la naturaleza, sino, al contrario, la física -y ello porque es ya pura teoría- emplaza a la Naturaleza a presentarse como una trama de fuerzas calculable de antemano ${ }^{36}$.

Por tanto, la ciencia moderna es consecuencia de la actitud técnica moderna, y no al revés:

Como la esencia de la técnica moderna descansa en la estructura de emplazamiento, por esto aquella tiene que emplear la ciencia natural exacta. De ahí surge la apariencia engañosa de que la técnica moderna es ciencia natural aplicada ${ }^{37}$.

El sistema tecnológico parece ser, por tanto, un poder autónomo que determina toda nuestra visión de la realidad y condiciona nuestras posibilidades de actuación. El paso de la técnica tradicional a la moderna significa una ruptura radical que modifica la condición humana y su forma de ver el mundo. Aunque en principio ese cambio comporta una negatividad evidente, también Heidegger deja la puerta abierta a la posibilidad de que nuestra reflexión sobre la producción y nuestro conocimiento pueda desembarazarse de la visión calculadora o utilitarista y restaure una sabiduría que acoja la revelación del ser ${ }^{38}$. Después de todo, la imposición (Gestell) es un destino (Geschick) del ser: el ser se oculta desocultando como imposición ${ }^{39}$.

Del mismo modo, la manifestación del aburrimiento en su sentido metafísico (el tedio) afecta a la totalidad del ser y nos permite entender nuestra situación existencial general, ofreciéndonos la posibilidad de transformar nuestra vida y espolear nuestra

36 HeIDEGGER, M. "La pregunta por la técnica", en Conferencias y artículos. Barcelona, Serbal, 2001, p. 23.

37 lb., p. 24.

38 Partiendo de esos fundamentos sobre la técnica, en su conferencia Construir, habitar, pensar -presentada en el congreso de arquitectos de Darmstadt de 1951-, Heidegger planteará en qué sentido el construir es propio del habitar humano. A ese mismo congreso acudió José Ortega y Gasset, que en su escrito En torno al coloquio de Darmstadt criticaría esa concepción heideggeriana del "habitar" originario del hombre en la Naturaleza y reivindicaría el carácter instrínsecamente técnico, provisional y proyectivo de la vida humana: "El auténtico y pleno wohnen -habitar- es una ilusión, un deseo... El hombre ha aspirado siempre a wohnen, pero no lo ha conseguido nunca del todo. Sin habitar no llega a ser. Por esta causa se esfuerza en ello y produce edificios, caminos, puentes y utensilios" (Ortega y Gasset, J. "En torno al coloquio de Darmstadt", en Meditación de la técnica y otros ensayos sobre ciencia y tecnología. Madrid: Alianza, 1982, p. 133). Es decir, que sin técnica no hay hombre. Eso quería expresar Ortega cuando afirmaba que la tierra es inhabitable para el hombre y que no podemos pensar al ser humano allende la técnica sin caer en la mitología. 39 Cfr. Rodríguez, R. Heidegger y la crisis de la época moderna. Madrid, Síntesis, 2005, p. 164. 
determinación ante el mundo, lo que puede propiciar un nuevo despertar del hombre. Paradójicamente, la indiferencia total del mundo brinda posibilidades ocultas a nuestro modo de ser: tenemos que enfrentarnos a nosotros mismos, a nuestra existencia nuda, y no podemos escapar a la situación, estamos forzados a afrontarla y hemos de encarar su verdad. En el fondo, la experiencia del tedio pone de manifiesto que el ser humano es productor o creador del significado de su vida y de su libertad.

Al despertar a la afección del tedio nos situamos en una posición más idónea para tener acceso al tiempo y al sentido del ser, es decir, para hacer verdadera filosofía. Cuanto más profundo es el tedio, mayor es nuestro enraizamiento en la temporalidad que somos. Nuestro primero afán es intentar "apagar el grito del aburrimiento mediante el pasatiempo, para así eliminar la necesidad de escucharlo"40, y ahí la técnica también cumple su función en la proliferación de poderosos medios recreativos de masas como el cine o la televisión, entre otros muchos, pero en el tedio se impone la obligación de escuchar, una obligación que domina en todo Dasein y que está relacionada para Heidegger con la más íntima libertad. En el tedio nos vemos obligados a reflexionar sobre la propia libertad, en lugar de olvidarla o malgastarla, ya que todo se derrumba y queda reducido a una única indiferencia: "El ente se convierte en indiferente como totalidad"41 y nosotros estamos incluidos en esa indiferencia, dejando de ser sujetos.

En el tedio el Dasein queda entregado a una totalidad de entes que se retiran, lo que, por negación, apunta a las posibilidades reales del Dasein. El tedio puede funcionar incluso como una iniciación a la metafísica, puesto que en él se hallan el mundo como un todo y lo individual, vinculados por su relación con una misma nada. El tedio pone de manifiesto un vacío, una indiferencia, una falta de sentido, una pérdida de mundo, pero a la vez impulsa la atención a la cotidianidad de las cosas y nos desplaza de la vida inauténtica. El efecto deshumanizante de la pérdida de sentido, que revierte en un mundo que se convierte en no-hogar, en un repertorio de productos vacíos y efímeros, también encuentra su paralelismo en la técnica.

Para Heidegger la plena identificación entre lo ente y el ser es lo que expresa el término "nihilismo" y lo que quiere decir la técnica: el final y la consumación de la historia de la metafísica:

40 HeidegGer, M. Los conceptos fundamentales de la metafísica. Mundo, finitud, soledad. Op. cit, p. 172.

$41 \mathrm{lb}$. 
El mundo de la tecnificación y de la organización calculada y racionalizada del planeta fruto de la aplicación de las ciencias habría estado ya inscrito, como futuro a alcanzar, en el pasado de la metafísica ${ }^{42}$.

El hombre actual se ha convertido en funcionario de la técnica: se caracteriza por un funcionamiento instintivo o automático de la razón y una racionalización de sus instintos. Incluso la mutua dependencia y necesidad entre el hombre y el ser se ha estandarizado en una tecnificación integral. Esta planificación abarca todos los dominios de nuestra vida: "la naturaleza, la sociedad, la economía, el comercio, la demografía, el tráfico, la cultura, la vida familiar, la educación, etc"43. No sólo todo lo real, sino incluso todo lo posible, está dominado por la técnica. No sólo todo lo verdadero, sino también lo pensable, se encuentra atrapado por su dispositivo. El hombre deja de ser sujeto y en cierto modo deja de ser hombre, al abandonar toda interrogación de apertura al ser y rendirse a la maquinaria del cálculo universal.

\section{La maquinación: el nihilismo de la técnica.}

Si en Ser y tiempo, como hemos visto, Heidegger analizaba la angustia y al aburrimiento, en Contribuciones a la filosofía (Del acontecimiento) se ocupa del espanto ante el fenómeno de la maquinación: este estado de ánimo se caracteriza por provocar un sobresalto repentino y una sacudida de nuestra conciencia, que aparece domesticada por la estructura de los mass media y la opinión pública: "El espanto en el abandono del ser y la reserva que se funda en tal espanto en cuanto creador"44. En obras posteriores Heidegger sustituirá la experiencia del espanto por la de la serenidad o el desasimiento, como formas de resistirse a la dominación de la técnica. De esta manera, sería posible liberarse de la servidumbre ante los objetos técnicos y aproximarse al ser en su modalidad más pura.

En nuestra época es la técnica la que instrumentaliza todo, incluido al ser humano, integrando a la teoría en su propio procedimiento y volviéndose así el lugar de la verdad, de la alétheia, del desvelamiento de la naturaleza, del hombre, de la ciencia, la cultura, la política... La técnica impone el modo de ser de las cosas. La técnica es el ser mismo,

42 SÁnchez MeCA, D. El nihilismo. Perspectivas sobre la historia intelectual de Europa. Madrid, Síntesis, 2010, p. 162.

43 lb., p. 186.

44 Heidegger, M. Contribuciones a la filosofía (Del acontecimiento). Santiago de Chile, Contenido, 1995, p. 28. 
entendido metafísicamente como voluntad de poder ${ }^{45}$, como producción del ser. Y el "nihilismo" significa precisamente ese predominio absoluto de lo ente, más allá del ser.

En la técnica

se hace posible por vez primera la verdad lógica total, que coincide en efecto con el despojamiento total: no caben representaciones o proyectos que todavía enmascararan la ausencia por medio de un significado, sino el reconocimiento de que todo es nada ${ }^{46}$.

El ser así entendido es, por tanto, nada. Pero este nihilismo del ser, que mejor manifiesta lo que hay, es condición para pensar y nombrar el ser simplemente como la cosa: qué sea la cosa es una posibilidad abierta cuando todas las cosas se han vuelto iguales.

La cosa -das Ereignis- se vuelve posible gracias a la tachadura del ser: cuando el ser es des-encubrimiento total, que ya no tiene opuesto, puede suspenderse. El ser, en efecto, se puede tachar porque tampoco pasa nada ${ }^{47}$.

Al igual que Spengler, Heidegger pensó que Occidente se despeñaba por el abismo del nihilismo europeo. Todo se encuentra bajo la maquinación, bajo el dominio del hacer y de la técnica. Ya no queda nada que no se presente conforme a la posibilidad del hacer y del ser hecho:

Lo que amenaza al hombre en su esencia es la opinión de que la producción técnica pone al mundo en orden, mientras que es ese orden el que nivela a todo ordo o todo rango en la uniformidad de la producción y, de este modo, destruye de antemano el ámbito del posible origen de un rango y reconocimiento a partir del ser. (...) La esencia de la técnica solo surge a la luz del día lentamente. Ese día es la noche del mundo transformada en mero día técnico. Ese día es el día más corto. Con él nos amenaza un único invierno infinito ${ }^{48}$.

La maquinación es este poder violento y metafísico que corre por el mundo tejiendo relaciones basadas sólo en el interés, favoreciendo la masificación y la factibilidad sin

\footnotetext{
45 Nietzsche, para Heidegger, es la culminación de la metafísica: el reconocimiento de que el lugar de las ideas, como lugar de la verdad, está vacío y no es nada. Para caracterizar esta nada queda reservado el término "nihilismo": solo las cosas en su eterno devenir revelarían la eterna verdad del ser. Pero este devenir es la propia voluntad de poder, cuyo principio de funcionamiento es el arte, es decir, la producción y la técnica.
}

46 LEYTE, A. Heidegger: el fracaso del ser. Barcelona, Batiscafo, 2015, p. 76.

47 Ib., p. 77.

48 Heidegger, M. "¿Para qué poetas?". En Caminos de Bosque, Alianza, 1995, p. 219. 
límite, consumiendo el ente y reduciendo todo a cálculo, vaciando y esclavizando a la realidad (a la que priva de sentido), convirtiendo el espíritu en un fantasma y dejando al Ser sin potencia ${ }^{49}$. Esto conduce también a la desertización de la tierra, al desarraigo, a la falta de suelo y de patria (en el sentido que le dio Hölderlin). Es un tiempo de clausura de horizontes, de extrema penuria e indigencia de pensamiento. El desarraigo del hombre es un hecho y sólo nos quedan puras relaciones técnicas, como afirmó Heidegger en la entrevista de Der Spiegel: ahora "todo funciona", "el funcionamiento lleva siempre a más funcionamiento" y "la técnica arranca al hombre de la tierra cada vez más y lo desarraiga". La técnica sería la prefiguración del Ereignis entre el hombre y el Ser:

(El ser) necesita del hombre, el ser no es ser sin que el hombre le sea necesario para su manifestación, salvaguardia y configuración. La esencia de la técnica la veo en lo que denomino la "im-posición" (Ge-stell) (...). El imperio de la "im-posición" significa: el hombre está colocado, requerido y provocado (herausgefordert) por un poder que se manifiesta en la esencia de la técnica. Precisamente en la experiencia de que el hombre está colocado por algo que no es él mismo y que no domina, se le muestra la posibilidad de comprender que el hombre es necesitado por el $\mathrm{Ser}^{50}$.

Frente a esta situación, Heidegger reivindicará para la filosofía una actitud de meditación y silencio, de devoción y serenidad, que envuelva la experiencia de la realidad en algo casi sagrado, de modo parecido a la poesía de Hölderlin o a la mística del maestro Eckhart. La maquinación y la vivencia propias del mundo técnico deben ser sustituidas por la meditación y el pensar rememorante ${ }^{51}$. Bordeando de nuevo la presencia de la nada, Heidegger asimila la ausencia de Dios en Hölderlin a la actual época de dominación técnica ${ }^{52}$. Sin necesidad de rendirse al pesimismo o de anunciar el fin de la filosofía, lo que Heidegger pretende es volver la mirada a lo esencial y recuperar la originaria apertura del ser, permaneciendo alerta y a la escucha de su misteriosa llamada ${ }^{53}$.

49 Cfr. Di CESARE, D. Heidegger y los judíos. Los Cuadernos negros. Barcelona, Gedisa, 2017.

50 HeIDEGgeR, M. Escritos sobre la Universidad alemana. Madrid, Tecnos, 1989, p. 72.

51 Cerezo Galán, P. "La cuestión del nihilismo. La confrontación Heidegger/Nietzsche". En SÁEZ, L, De LA Higuera, J. y ZúÑIGA, J.F. (eds.): Pensar la nada. Ensayos sobre filosofía y nihilismo. Madrid, Biblioteca Nueva, 2007, p. 262.

52 Cfr. Heidegger, M. "¿Para qué poetas?". Op. cit.

53 Para un análisis del carácter poético de la física cuántica, véase ROMERo MARTínEZ, J.M. "Poética, naturaleza y desocultación en la mecánica cuántica: Una propuesta heideggeriana", en Differenz. Revista internacional de estudios heideggerianos y sus derivas contemporáneas. № 2, 2016, pp. 202-219. 


\section{Conclusión: ¿Una superación del nihilismo?}

Realizado el recorrido por las múltiples y ambivalentes relaciones entre los conceptos de la nada, el tedio y la técnica en la obra de Heidegger, podemos preguntarnos si cabe hablar de una superación del nihilismo en su filosofía. Federico Vercellone ${ }^{54}$ explica que la diferencia principal entre Jünger y Heidegger en su planteamiento sobre el nihilismo estriba en que Jünger entiende el über de su escrito Über die Linie como "más allá de", es decir, como superación, como sobrepasamiento de la línea del nihilismo, mientras que Heidegger entiende el término über como "sobre", es decir, tratando de definir más ajustadamente las características del fenómeno del nihilismo pero asumiendo la imposibilidad de un soprepasamiento no metafísico de la metafísica ${ }^{55}$. Para Jünger trazar la línea que circunscribe el nihilismo es el modo de superarlo; para Heidegger, en cambio, no lo es. El acabamiento de la metafísica en la época de la técnica significaría para Heidegger su consumación como perfeccionamiento ilimitado, pasando del ámbito de la teoría a su materialización efectiva en la estructura de lo real ${ }^{56}$.

Por su parte, Franco Volpi considera que lo decisivo es entender dónde se halla la línea, dónde y cuándo se produce su cruce: la superación del nihilismo. Según él, contrariamente a la impresión que suscitan las críticas de Heidegger, para Jünger la línea no es el punto final, sino que se sitúa dentro del nihilismo mismo y le señala su punto medio. Con la superación de la línea, por tanto, no estaría cumplido aún el cruce del nihilismo ${ }^{57}$. Para Juan Luis Vermal, una superación del nihilismo sólo es posible como un "pensar al encuentro" (entendido como un resignar o desdecir) que reconoce que el ser mismo se sustrae, "y que esta sustracción es la referencia que reivindica la esencia del hombre como el lugar de su advenir, como su ahí"58. Según Pedro Cerezo, "no se trata de una superación extrínseca, sino de un 'sobreponerse a' y 'reponerse de' la técnica -esto es, del imperialismo del pensamiento calculador"59.

54 Cfr. Vercellone, F. Introduzione a il Nichilismo. Roma, Laterza, 2009, p. 119.

55 Cfr. HeIDEGger, M.; JÜNGER, E. Op. cit.

56 El Gestell, como dispositivo tecnológico mundial, sería la ejecución definitiva de todas las revelaciones de la ontología del pasado: desde las ideas platónicas hasta la voluntad de poder nietzscheana, pasando por las causas aristotélicas, el Dios cristiano, la subjetividad cartesiana, la objetividad kantiana o el absoluto hegeliano, todo se ha fundido y transmutado finalmente en la técnica.

57 Cfr. VolPI, F. El nihilismo. Buenos Aires. Biblos, 2005, pp. 109-110.

58 VERMAL, J. L. "El origen negativo. Acerca de la nada y la negación en los Beiträge y en la concepción heideggeriana del nihilismo". En SÁEZ, L, DE LA HIGUERA, J. y ZúÑIGA, J.F. (eds.). Op. cit, pp. 299.

59 Cerezo Galán, P. "Metafísica, técnica y humanismo". En NaVArro Cordón, J. M. y Rodríguez, R. (Eds.). Heidegger o el final de la filosofía. Madrid, Complutense, 1993, p. 84. 
Sin embargo, queda planteada por Heidegger la posibilidad de pensar en un nuevo comienzo: la espera y conversión del hombre podrían llevar a una apertura del ser. Para poder responder a la pregunta filosófica por antonomasia que planteábamos al principio -"¿¡por qué es el ente y no más bien la nada?"- la filosofía debe liberarse del lenguaje instrumental y calculador de la técnica en que está sumido el hombre actual y volver a la esencial correspondencia entre el ser y el hombre, aceptándola como un don y mostrándola como un acontecimiento que se apropia de nosotros. Sólo así es posible la superación del nihilismo. Ereignis ${ }^{60}$ será el término utilizado por Heidegger para indicar esa originaria copertenencia de ser y hombre: por un lado, el ser es quien posibilita el aparecer de las cosas y de los hombres; por otro, el ser como iluminación no podría darse sin el hombre.

Para Heidegger el hombre necesita una nueva actitud filosófica y una manera distinta de acercarse a la realidad inmediata, al margen de los dictámenes de la explotación, la dominación, la productividad o la rentabilidad, en actitud de escucha y espera para recuperar su originaria relación con el ser. La serenidad de la meditación filosófica frente al vértigo de la voluntad de poder, silencio frente a ruido, devoción frente a funcionamiento, en espera y en escucha del Ser. Aunque en los textos de Heidegger no aparezca siquiera sugerida esta hipótesis, queríamos terminar apuntando la posibilidad de que fuera precisamente la experiencia del tedio, en su indiferencia ante el dispositivo, en su evidenciar la nihilidad esencial de la maquinación, en su poner de manifiesto la ausencia de sentido y de cuidado de la tecnificación planetaria, en su capacidad de detención del tiempo y en su revelación del vacío de la existencia automatizada, que fuera -repito- la experiencia del tedio la que, más allá del éxtasis místico o de la palabra poética, efectuase una tarea de "des-composición" del Gestell que pueda liberar al hombre de la servidumbre, del extrañamiento, del desarraigo, de la desertización, e inaugurase, al menos parcialmente, la posibilidad de una apertura al ser, a la vida auténtica, al hogar del mundo.

\section{Referencias bibliográficas.}

CEREzo Galán, P. "Metafísica, técnica y humanismo". En Navarro Cordón, J. M.; Rodríguez, R. (Eds.): Heidegger o el final de la filosofía. Madrid, Complutense, 1993, pp. 59-92.

60 Se puede traducir como "acontecimiento" o como "apropiación". 
Cerezo Galán, P. "La cuestión del nihlismo. La confrontación Heidegger/Nietzsche". En SÁEZ, L.; De LA Higuera, J.; Zúñiga, J.F. (eds.). Pensar la nada, Ensayos sobre filosofía y nihilismo. Madrid, Biblioteca Nueva, 2007, pp. 201-262.

DI CeSARE, D. Heidegger y los judíos. Los Cuadernos negros. Barcelona, Gedisa, 2017.

GabÁs, R. "Martin Heidegger: Caminos hacia el ser". En HiRSCHBerger, J. Historia de la Filosofía III. Filosofía del siglo XX. Barcelona, Herder, 2011, pp. 88-212.

GUMBRECHT, H. U. Stimmungen lesen: Über eine verdeckte Wirklichkeit der Literatur. Munich, Hanser, 2011, p. 125.

HeIdegger, M. ¿Qué es metafísica? Tr. X. Zubiri. Buenos Aires, Siglo Veinte, 1967.

HeIDegGeR, M. Introducción a la metafísica. Tr. A. Ackermann. Barcelona, Gedisa, 1987.

HeIDEGgER, M. Escritos sobre la Universidad alemana. Tr. R. Rodríguez. Madrid, Tecnos, 1989.

HeIdegger, M.; Jünger, E. Acerca del nihilismo. Tr. J. L. Molinuevo. Barcelona, Paidós, 1994.

Heidegger, M. Contribuciones a la filosofía (Del acontecimiento). Tr. P. Oyarzun. Santiago de Chile, Contenido, 1995.

Heidegger, M. "¿Para qué poetas?". En Caminos de bosque. Tr. A. Leyte y H. Cortés. Madrid, Alianza, 1995.

HeIDEgGER, M. Nietzsche II. J. L. Vermal. Barcelona, Destino, 2000.

Heidegger, M. ¿Qué es la filosofía? Tr. J. Adrián. Barcelona, Herder, 2004.

Heidegger, M. Los conceptos fundamentales de la metafísica. Mundo, finitud, soledad. Madrid, Alianza, 2007.

Heidegger, M. "La pregunta por la técnica". En Conferencias y Artículos. Tr. E. Barjau. Barcelona, Serbal, 2001.

Heidegger, M. Carta sobre el humanismo. Tr. A. Leyte y H. Cortés. Madrid, Alianza, 2013. HeIdegger, M. Ser y tiempo. Tr. J. E. Rivera. Madrid, Trotta, 2018.

LEYTE, A. Heidegger. Madrid, Alianza, 2005.

LEYTE, A. Heidegger: el fracaso del ser. Barcelona, Batiscafo, 2015.

MANSIKKA, J. E. "Can boredom educate us? Tracing a mood in Heidegger's fundamental ontology from an educational point of view", en Studies in Philosophy and Education. № 28, 3, 2009, pp. 255-268. 
ORTEGA y GASSET, J. "En torno al coloquio de Darmstadt". En Meditación de la técnica y otros ensayos sobre ciencia y tecnología. Madrid: Alianza, 1982.

Rodríguez, R. Heidegger y la crisis de la época moderna. Madrid, Síntesis, 2005.

RoMero MARTínez, J. M. "Poética, naturaleza y desocultación en la mecánica cuántica: Una propuesta heideggeriana", en Differenz. Revista internacional de estudios heideggerianos y sus derivas contemporáneas. № 2, 2016, pp. 202-219.

Sánchez Meca, D. El nihilismo. Perspectivas sobre la historia intelectual de Europa. Madrid, Síntesis, 2010.

SeVerino, E. Essenza del nichilismo. Milano, Adelphi, 2005.

SLABY, J. "The other side of existence: Heidegger on boredom". En FLACH, S.; MARGULIES, D.; SÖFfNER, J. Habitus in Habitat II-Other Sides of Cognition. Bern, Lang, 2010, pp. 101120.

SVEndSEN, L. Filosofía del tedio. Tr. C. Montes. Barcelona, Tusquets, 2006.

VERCELlone, F. Introduzione a il Nichilismo. Roma, Laterza, 2009.

Vermal, J. L. "El origen negativo. Acerca de la nada y la negación en los Beiträge y en la concepción heideggeriana del nihilismo". En SÁEZ, L., DE LA HIGUERA, J. y ZÚÑIGA, J. F. (Eds.). Pensar la nada. Ensayos sobre filosofía y nihilismo. Madrid, Biblioteca Nueva, 2007, pp. 283-300.

VolPI, F. El nihilismo. Tr. C. I. del Rosso y A. G. Vigo. Buenos Aires, Biblos, 2005. 